\title{
Teaching blind women about the anatomy and physiology of the female reproductive system through educational manual
}

\author{
Mariana Gonçalves de Oliveira 1 \\ Aline Cruz Esmeraldo Áfio 2 \\ Paulo Cesar de Almeida 3 \\ Márcia Maria Tavares Machado 4 \\ Ana Cristina Lindsay 5 \\ Lorita Marlena Freitag Pagliuca 6
}

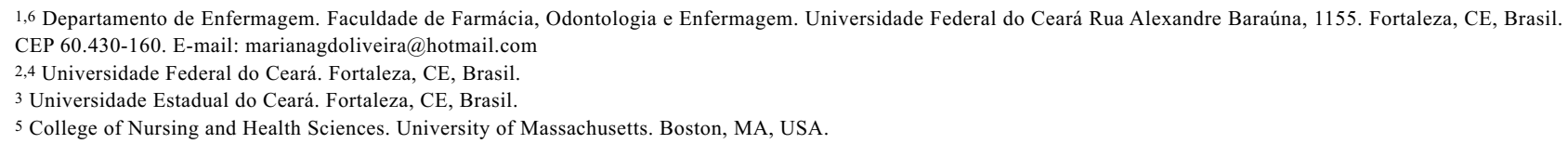

\begin{abstract}
Objectives: to evaluate blind women's learning on the anatomy and physiology of the female reproductive system through the use of an educational material.

Methods: methodological development study performed with blind women. The participants responded the pre-test to evaluate their knowledge on sexual and reproductive health and received a manual on anatomy and the reproduction of the physiology After an individual reading, in a period ranging from three to fifteen days, they responded the post-test.

Results: there was an increase of correct answers in the post-test in all the items in relation to the categories of The Woman's Body and How One Gets Pregnant becoming significant in the following knowledge of "clitoris increases with the woman excited" ( $p=0.009)$, "the function of the vagina in a sexual intercourse " $(p<0.001)$, "How does fertilization occurs" $(p<0.001)$ and "the ovulating period" $(p<0.001)$.

Conclusions: the manual enabled the participants to learn about the female anatomy and the physiology of fertilization after educational assistive technology.

Key words Visually impaired, Sexuality, Self-help devices, Nursing education, Nursing care
\end{abstract}

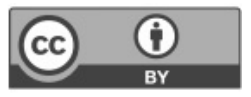




\section{Introduction}

Stigmas about the disabled population's sexuality are still present in the XXI century, it is believed that men and women under this condition cannot have children or even have sexual intercourse.1-3 However, a survey conducted with 426 disables people identified that $52 \%$ are sexually active and $75 \%$ have started their sexual life between the age of 15 and 19 years old. 4

In Brazil, there are more than 6.5 million people that have visual impairment 582,000 are blind women and 6 million have low vision. ${ }^{5}$ According to World Report on Disability and Vision, every 5 seconds 1 person becomes blind in the world. About 39 million people in the world are blind and another 246 million have low vision. In addition, the total blindness cases, $90 \%$ occur in emerging and underdeveloped countries. It is estimated that by 2020 , the number of people with visual impairment in the world might double. 6

Regarding to women with disabilities, the experience of dual vulnerability is perceived, due to the inequality of gender to disabled women are imposed barriers to social and political participation, access to education, justice and work. In addition, common sense creates prejudices about blind woman when it considers that she does not fit in current esthetic models and cannot arouse the interest of another person by being diffused and that she cannot assume the role of a caregiver, wife and mother. ${ }^{7}$

Issues about disabled women's sexuality go beyond social environment and are inserted in the health care area Health actions for this population are inexpressive in the Primary Care services and the lack of physical and communicational accessibility are factors that need to be reviewed. In addition, professionals need to be sensitive and trained to be able to work with these women who have specificities. Despite the female clientele have privilege in the health units, disabled women suffer violation of their sexual and reproductive rights. ${ }^{2}$ The consequences of this behavior are aggravated when combined with the lack of health educational materials adapted and accessible to the blind population. ${ }^{8}$

Educational technologies can be quite effective as a strategy in preventing and promoting health in general. Thus, an educational manual justifies the lack of accessible materials that address themes related to sexuality.

Given to this context, one can see the relevance of this subject and the necessity to promote health for blind women who wish to obtain knowledge about the anatomy and the functioning of their body.
Providing knowledge about aspects related to sexuality is also a nursing care. Thus, considering that the research proposed here is significant, as well as to provide reflection on the theme can provide new approaches on sexual education. The objective of this study was to evaluate blind women on learning about the anatomy and physiology of the female reproductive system through the use of an educational manual.

\section{Methods}

This is a methodological development study carried out between November 2014 and February 2016, in Fortaleza city in Ceará State. The study included women older than 18 years with congenital or acquired blindness, literate in Braille or able to perform extended text reading. We excluded women with hearing impairment who had already used the manual used here in previous studies.

The Participants were from different locations such as their home or job place, recreational associations and educational institutions. To select the sample a snowball technique was used in which each participant indicated another participant and so on, constituting a non-probabilistic convenience sample due to a restriction sample.

The study evaluated the blind women's learning on female anatomy and reproductive physiology after reading an educational manual constructed and validated in a previous study. ${ }^{9}$ The Manual is divided into chapters: The Women's Body; How One Gets Pregnant; Talking about contraceptives; Behavioral contraceptive methods. This study focused on the first two chapters that address the women's reproductive system where presents the female anatomy, the internal and external organs and their functions approach as well as the physiology of fertilization. The Material is printed in Braille and simultaneously the ink with embossed and described figures, that is, it has textual equivalence, thus facilitating its comprehension for the blind reader.

To apply the manual, an interview was initially held with each participant and the pre-test tool was used to evaluate their knowledge about sexual and reproductive health. Then, the participant received the manual for individual reading in a deadline which varied between 3 and 15 days, according to each one's necessity. In a second meeting, the posttest tool was filled out to evaluate their learning. 10 The pre and post-test tools were identical. These tools were elaborated from the contents of the manual with affirmations on the theme and the tools and the Manual were validated by specialist. 
The data were compiled in the Statistical Package for Social Sciences (SPSS) software. Cronbach's Alpha coefficient was used for reliability analysis; the McNemar's test was used to verify significance of changes; McNemar's odds ratio was used to verify the reason on learning chances after using the manual; and the Wilcoxon test was used to compare before and after correction averages.

The development of this study met the national and international norms of the research ethics involving human subjects. The research was approved by the Committee of Ethics and Research (COMEPE - Comitê de Ética e Pesquisas) at the Universidade Federal do Ceará (UFC) under the number of the document 851.454 .

\section{Results}

48 blind women participated and most of them $(52.1 \%)$ had congenital blindness. The age ranged from 18 to 66 years with a mean of $35 \pm 14$ years, prevailing the age range of 18 to 29 years old $(42 \%)$. Women with higher education prevailed $(40 \%)$, followed by High School (30\%), and the prevailing civil status was single $(56 \%)$.

The correctness of the questions on The Women's Body and How One Gets Pregnant, according to the type of blindness and sociodemographic characteristics were observed (Table 1).
Regarding the Women's Body category, participants with acquired and congenital blindness, in the age group of 18 to 39 years old, in any schooling level or marital status presented high scores of mean corrections between pre-test and post-test with statistical significance $(p<0.001)$.

Already in the category How One Gets Pregnant significant results were obtained among women with acquired blindness in the age group of 18 to 29 years old and those 40 years old or more, with complete Elementary Schooling and married or in a commonlaw-marriage.

It was also found that when the blind woman used the educational manual, she was twice as likely to learn about the above issues, as observed in Table 2 .

Regarding the questions to the Women's Body category, it was verified that the educational intervention was essential to increase the learning regarding to the clitoris increases with an aroused woman ( $p=0.009)$ and the function of the vagina in a sexual intercourse $(p<0.001)$.

Among the three questions in How One Gets Pregnant category, those on how does fertilization occur and the period of ovulating presented an increased learning after reading the manual $(p<0.001)$, with four times the chances.

This study identified that approximately $50 \%$ of the blind women made six affirmative mistakes of

Table 1

Comparison of the correction means between pre and post-test according to sociodemographic characteristics. Fortaleza, CE, Brazil, 2017.

\begin{tabular}{|c|c|c|c|c|c|c|}
\hline \multirow[t]{2}{*}{ Variables } & \multicolumn{3}{|c|}{ The Women's body } & \multicolumn{3}{|c|}{ How one gets pregant } \\
\hline & Pre-test & Post-test & $p^{*}$ & Pre-test & Post-test & $p^{*}$ \\
\hline \multicolumn{7}{|l|}{ Blindness } \\
\hline Acquired & 3.82 & 6.17 & $<0.001$ & 2.00 & 2.652 & 0.01 \\
\hline Congenital & 3.72 & 5.44 & $<0.001$ & 2.00 & 2.36 & 0.063 \\
\hline \multicolumn{7}{|l|}{ Age group (years) } \\
\hline $18-29$ & 3.85 & 5.5 & $<0.001$ & 1.95 & 2.4 & $<0.143$ \\
\hline $30-39$ & 3.2 & 5.66 & $<0.001$ & 1.93 & 2.2 & 0.330 \\
\hline$\geq 40$ & 4.30 & 6.38 & 0.006 & 2.07 & 2.61 & 0.041 \\
\hline \multicolumn{7}{|l|}{ Schooling } \\
\hline Elementary School & 3.00 & 4.7 & 0.03 & 1.6 & 2.4 & 0.04 \\
\hline High School & 4.052 & 6.00 & $<0.001$ & 2.157 & 2.578 & 0.096 \\
\hline Higher Education & 3.894 & 6.157 & $<0.001$ & 2.052 & 2.4736 & 0.098 \\
\hline \multicolumn{7}{|l|}{ Marital Status } \\
\hline Single & 3.85 & 5.55 & $<0.001$ & 2.074 & 2.481 & 0.051 \\
\hline Married/Common-law-marriage & 3.66 & 6.09 & $<0.001$ & 1.90 & 2.52 & 0.012 \\
\hline
\end{tabular}

*Post-tests marked by Wilcoxon. 
Distribution of the number of blinds according to the correct answers in the pre and post-test on the Women's Body and How one Gets Pregnant. Fortaleza, CE, Brazil, 2017.

\begin{tabular}{|c|c|c|c|c|}
\hline Variables & Pre-test & Post- test & $p^{*}$ & OR (Cl95\%) \\
\hline \multicolumn{5}{|l|}{ The Women's Body, you know: } \\
\hline What is a vulva & 20 & 31 & 0.794 & $1.10(0.63-1.95)$ \\
\hline Clitoris increases with an aroused woman & 29 & 40 & 0.009 & $2.10(1.22-4.14)$ \\
\hline What is "Mount Venus" & 25 & 37 & 0.093 & $1.60(0.94-2.96)$ \\
\hline What is perineum & 15 & 33 & 1.000 & $1.00(0.59-1.69)$ \\
\hline The function of a vagina in intercourse & 34 & 38 & $<0.001$ & $2.71(1.50-6.19)$ \\
\hline What is a hymen & 19 & 32 & 0.797 & $1.10(0.76-2.39)$ \\
\hline Location of urinary excretion & 24 & 39 & 0.777 & $1.62(0.96-2.95)$ \\
\hline Location of vaginal canal & 15 & 29 & 0.703 & $0.87(0.50-1.5)$ \\
\hline \multicolumn{5}{|l|}{ About How One Gets Pregnant, they know: } \\
\hline How does fertilization occur & 38 & 45 & $<0.001$ & $4.5(2.415-3.125)$ \\
\hline Ovulating period & 38 & 40 & $<0.001$ & $4(2.117-11.638)$ \\
\hline The period during which pregnancy can occur & 20 & 35 & 0.449 & $1.25(0.739-2.187)$ \\
\hline
\end{tabular}

*McNewmar Test. OR= odds ratio; CI95\%=95\% confidence interval.

those eight analyzed on the Women's Body with an increase in the significant knowledge about the clitoris and the function of the vagina in a sexual intercourse after reading the manual. In addition, regarding to the category How One Gets Pregnant, only 20 of the 48 participants had the knowledge about fertile period.

\section{Discussion}

There was a significant increase in the knowledge of the blind women with acquired and congenital deficiency. There is evidence that people with congenital blindness present more curiosity about health information, despite the difficulty of understanding, being present the interest on sexual and reproductive health in a research carried out with 31 people with visual impairment. ${ }^{11}$ The quality of the manual for teaching women with congenital and acquired blindness is perceived.

A survey of 352 disabled people on contraceptive methods in the cities of Kenya, Nepal and Uganda identified that young people have limited knowledge about sexual and reproductive health. 12 This result is in line with this study, in which women who were in the age group of 18 to 39 years old had a low correction rate in the pre-test when compared to women over 40 years old, despite of the increase in the post-test scores in all age groups evaluated showing a positive impact on learning after using the evaluated technology.

It is noted that the information given to adoles- cents about sexuality and contraception is sufficient. Evidence shows that there is a necessity for programs and materials that can bring changes in these young people's behavior. It is recommended to train health professionals and teachers at schools. 13

The response to this problem is education: one in five unmarried adults say they have never had sexual education in school and among those who have had, only one forth had sexual education before the age of 15 . Adding to this, the rates are high for young adults when they are confusion and misinformed about fertility and contraception. 14 In this sense, the necessity for direct and organized education is suggested, which presents basic information on anatomy, fertility, pregnancy and sexually transmitted infections, in order to neutralize and correct myths and misinformation.

Sexual risk behavior and sexual health inequalities may be even greater among vulnerable young people and minor ethnic, who may also be negatively influenced by a number of factors, such as the father's absence at home, low self-esteem, the lack of skills (for example, the use of condom) the lack of negotiation skills, ) (eg, to say "no" to sex without condoms), the lack of knowledge about the risks of different sexual behaviors and availability of resources such as condoms or sexual health services, peer pressure; and the society's attitudes and prejudices which may affect young people's access to the services. 15 For blind women and in addition to these difficulties faced by young people, there is prejudice related to disability and sexuality. 
The Demographic Census results show that the 15 years old or more population with disability does not have any schooling or only have an incomplete Elementary Schooling (61.1\%), compared to the public that declared not have anything (38.2\%). Among the women with some deficiency the minority present to have Higher Education. ${ }^{16}$ This fact may be associated with the difficulty of accessing school, materials and interpersonal relationships.

On the other hand, the prevalence in this study of young adults and adults presented a high level of schooling, prevailing the higher education (40\%). After reading the manual the learning was similar to Elementary and high schooling, as both revealed statistical significance in the category of the Women's Body.

The results showed a prevalence of single blind women (56\%). Researchers argue that interpersonal relationships and social interactions are impaired in most of the blind individuals, since the limitation of the vision causes natural isolation in this population. 17

The deficit of blind knowledge about the anatomy of the female body and the physiology of reproducing can be justified by the society's prejudices about the sexuality of disabled people. Studies indicate that family members and health professionals deny the existence of sexuality among blind women believing that they are asexual, becoming dependent, considered to be infantile and incapable of enjoying adult sexual life.1,2,18 This is because the contemporary society associates the reproductive and genital function with the individual's physical aspects forgetting that sensuality and eroticism are related to the psychological scope of each human being.

A qualitative research conducted with six men and five women showed that blind women feel excluded when the subject is sexuality, including the health system. They affirm that, although they have their rights guaranteed by various public policies, when it comes to the Brazilian Federal Government programs such as the prevention on sexually transmitted diseases, HIV and AIDS are not contemplated. In addition, they demand adequate teaching and learning resources to meet their necessities. 19

Considering that a blind woman is not endowed with sexuality, her rights to access sexual orientation and education are neglected. There is no incentive to these programs because they are believed to be unnecessary. It is believed that addressing the issue, sexual practice is encouraged while in fact, sexual orientation would enable a safe, full, healthy and responsible practice. Thus, the importance of constructing and applying accessible educational resources for teaching and learning the blind about sexuality.

Integrative literature review 20 evaluated the effects of educational interventions using educational technologies on contraceptive methods in 15 articles and identified a statistically significant improvement in knowledge about contraceptive risks, benefits, side effects, efficacy and mode of use in 14 studies with different population involving men and/or women over 18 years old. These data are in agreement with the findings of the manual evaluated, which, in addition to provide teaching about the female anatomy and the physiology of reproduction, they were shown to be four times more effective for increasing their knowledge on fertilization and ovulating period. This result indicates the relevance of sexual and reproductive health education activities for the acquisition of the essential information on health promotion.

The use of an educational manual as an aid tool based on scientific knowledge can promote health. Reading these materials can help patients, families and neighbors during the learning process and thus stimulate self-care, as well as make them understand the health-disease process. One of the advantages of educational resources is to standardize the guidelines to be studied and carried out by the health professionals. 21

Nursing professionals need to know the peculiarities in this population to be able to provide specialized and humanized care, according to the necessities of the blind women, as advocated in public policies.1,22 The educational manual will facilitate the inclusion of disabled women in the health services, according to the practice of the basic principles of the Brazilian Public Health System (Sistema Único de Saúde): universality, equity and comprehensiveness.

Despite the current debates on the disabled people's sexuality, the issue has still been neglected by the society, including the health professionals. It is inferred that blind women are still victims of prejudice, being exposed to unplanned pregnancy, sexual violence and sexually transmitted diseases. Disabled people are above all subjects of the law and, as such, must express their sexuality in a safe, autonomous and pleasurable way.

Despite the significant associations regarding to teaching blind women after reading the manual on the Women's Body and How One Gets Pregnant, the absence of a control group or comparisons did not allow to state their efficacy in relation to other 
educational interventions.

The manual allowed participants to learn about the female anatomy and the physiology of fertilization, adding previous knowledge to those acquired during reading. Statistical analyzes showed that, regardless to the type of blindness and sociodemographic characteristics, there was an increase in the scores, comparing to the pre and post-test reinforcing an excellent learning strategy.

Therefore, the research sought to solve a situation in practice, the lack of having information access on this subject about the theme, through the evaluation of the educational manuals being accessible to blind women. The present study should benefit the female clientele by allowing them to have access on the anatomy and physiology of their body, providing autonomy and independence, safe sex practice, full, healthy and responsible sexual prac- tice, a fact that can prevent unplanned pregnancies.

Among the implications of this study to practice is observed in the use of the manual in schools, family planning consultations, health education and promoting health activities, research on blind people and others.

Here, the subjects on sexual and reproductive health, specifically contraceptive behavioral methods were addressed but in the future, this Manual can be made up of other interesting topics, expanding the possibilities of its use in both health and education institutions and so include blind people. In addition, it was perceived for future perspectives, the use of other modalities that are not printed, like on spoken $\mathrm{CD}$, or an electronic address, or page on the Internet, or video description and others.

\section{References}

1. Tellier S. Advancing the discourse: disability and BDSM Sex Disabil. 2017; 35 (4): 485-93.

2. Oliveira MG, Moura ER, Evangelista DR, Pagliuca LM Health education teaching for blinds about natural contraceptive methods. Rev Enferm UFPE. 2013; 7 (7): 4732-9.

3. Chappell P. How Zulu-speaking youth with physical and visual disabilities understand love and relationships in constructing their sexual identities. Cult Health Sex. 2014; 16 (9): 1156-68.

4. Kassa TA, Luck T, Birru SK, Riedel-Heller SG. Sexuality and sexual reproductive health of disabled young people in Ethiopia. Sex Transm Dis. 2014; 41 (10): 583-8.

5. IBGE (Instituto Brasileiro de Geografia e Estatística). Censo Demográfico 2010. [acesso em 15 Jul 2018]. Disponível em: http://censo2010.ibge.gov.br/

6. WHO (World Health Organization). World report on disability. 2010 [acesso em 20 Jul 2018]. Disponível em http://www.larchetoronto.org/wordpress/wpcontent/uploads/2012/01/launch-of-World-Report-onDisability-Jan-27-121.pdf

7. Nicolau SM, Schraiber LB, Ayres JRCM. Mulheres com deficiência e sua dupla vulnerabilidade: contribuições para a construção da integralidade em saúde. Ciênc Saúde Coletiva. 2013; 18 (3): 863-72

8. Kelly SM, Kapperman G. Sexual activity of young adults who are visually impaired and the need for effective sex education. J Visual Impairment Blindness. 2012; 106 (9): 519-26.

9. Oliveira MG, Pagliuca LM. Construction of assistive technology for blind women: handbook on behavioral contraceptive methods. Creative Education. 2014; 5 (23): 1979 83.
10. Oliveira MG. Validação do manual saúde sexual e reprodutiva: métodos anticoncepcionais comportamentais para cegas. [tese]. Fortaleza: Universidade Federal do Ceará; 2016

11. Beverly CA, Bath PA, Barber R. Health and social care information for visually-impaired people. Aslib Proceedings. 2011; 63 (3): 256-74.

12. Tanabe M, Nagujjah Y, Rimal N, Bukania F, Krause S. Intersecting sexual and reproductive health and disability in humanitarian settings: risks, needs, and capacities of refugees with disabilities in Kenya, Nepal, and Uganda. Sex Disabil. 2015; 33 (4): 411-27.

13. Levy O, Cohen A, Hardoff D. Sexuality and reproductive health counselling for adolescents with disabilities. Rivista Italiana di Medicina dell'Adolescenza. 2014; 12 (1): 13-5.

14. Macedo, HSdR, Nunes de Miranda, FA, Pessoa Júnior, JM, de Medeiros Nóbrega, VK. Adolescência e sexualidade: scripts sexuais a partir das representações sociais. Rev Bras Enf. 2013; 66 (1): 103-109.

15. Hayford SR, Guzzo KB. Racial and Ethnic Variation in Unmarried Young Adults' Motivation to Avoid Pregnancy. Perspect Sex Reprod Health. 2013; 45 (1): 41-51

16. Straw F, Porter C. Sexual health and contraception. Arch Dis Child Educ Pract Ed. 2012; 97 (5): 177-84.

17. IBGE (Instituto Brasileiro de Geografia e Estatística). Censo demográfico 2010. [acesso em 23 Fev 2018]. Disponível em: http://www.ibge.gov.br/home/estatistica/ populacao/censo 2010

18. Agmon M, Sa'Ar A, Araten-Bergman T. The person in the disabled body: a perspective on culture and personhood from the margins. Int J Equity Health. 2016; 15 (147): 1-11.

19. Wanderley LD, Barbosa GOL, Rebouças CBA, Oliveira PMP, Pagliuca LMF. Sexualidade, DST e preservativo: 
comparativo de gênero entre deficientes visuais. Rev Enferm UERJ. 2012; 20 (4): 463-9.

20. França DNO. Direitos sexuais, políticas públicas e educação sexual no discurso de pessoas com cegueira. Rev Bioet. 2014; 22 (1): 126-33.

21. Zombini EV, Pelicioni MCF. Estratégias para a avaliação de um material educativo em saúde ocular. Rev Bras Cresc Desenv Hum. 2011; 21 (1): 51-8.
22. Dias JC, Santos WS, Kian GC, Silva PYF, Rodrigues LB. Os desafios da maternidade e a importância de ser mãe para mulheres com deficiências. Interfaces: Saúde, Hum Tecnol. 2014; 2 (6): 1-5.

Received on April 4, 2018

Final version presented on August 23, 2018

Approved on September 20, 2018 